\title{
STRATEGIJE UPRAVLJANJA GOTOVINOM KAO DOBRA PRAKSA U GLOBALNOM POSLOVANJU
}

\author{
Dragan Miletićił, Marko Milojevićc, Zoran Jović \\ ${ }^{1}$ Fondacija „Centar za mlade talente”, Narodnog fronta 25B/2, Novi Sad, Srbija \\ ${ }^{2}$ Univerzitet Singidunum, Poslovni fakultet u Beogradu, Danijelova 32, Beograd, Srbija
}

\begin{abstract}
Apstrakt:
Gotovina i obrtni kapital su visoko rangirani na listi korporativnih prioriteta. Kako bi se definisali kriterijumi i merila što efikasnijeg upravljanja gotovinom u visoko-konkurentnom okruženju, neke od poznatih revizorskih kuća definisale su poslovnu strategiju „potpunog keš menadžmenta”, koja u suštini predstavlja poslovnu strategiju upravljanja gotovinom. Primena ove strategije ima za cilj stvaranje vrednosti za vlasnike i učvršćivanje profitnih marži. Kako bismo uporedili primene navedene strategije upravljanja gotovinom i obrtnim kapitalom u Republici Srbiji u odnosu na inostrane kompanije, sprovedeno je istraživanje koje je imalo za cilj da utvrdi stanje prakse po bitnim elementima strategije „potpunog keš menadžmenta”. Na osnovu dobijenih odgovora uočene su sličnosti koje se pre svega odnose na značaj koji se pridaje upravljanju tokovima gotovine, likvidnosti i solventosti od strane rukovodstva inostranih i domaćih kompanija. Istraživanje je takođe ukazalo na sličnosti između praksi vezano za definisanje problema za unapređenje obrtnog kapitala i načina za postizanje željenih ciljeva. Uporedna analiza ukazala je na određene razlike u praksama inostranih i domaćih kompanija u pogledu optimalnog perioda za predviđanje tokova gotovine i prakse podsticanja menadžera putem bonusa u unapređenju upravljanja gotovinom. Trenutno stanje zahteva aktivniju primenu strategije „potpunog keš menadžmenta” u preduzećima u Republici Srbiji.
\end{abstract}

\section{Ključne reči:}

obrtni kapital, tokovi gotovine, poslovna strategija, previđanje, merila.

\section{UVOD}

Predviđanje je kritičan korak u strategiji keš menadžmenta u cilju povećavanja profitabilnosti. Suprotno tome, neadekvatno planiranje i neadekvatna kooridinacija unutar poslovnih funkcija, često se završava lošim procesima predviđanja i smanjenjem profitabilnosti. Da bi predviđanje bilo ažurno, menadžeri bi trebalo da obezbede da se ustanovi jasan format izveštaja, definiše na koga se računa da će dati važne cifre u izveštaju, kao i ko je odgovoran za reviziju podnetih izveštaja. Gotovina je „srce” svakog biznisa, u smislu jednog od glavnih indikatora kvaliteta poslovanja. Kompanije koje ovo shvate su u poziciji da razviju kulturu poslovanja u kojoj je svako odgovoran za gotovinu i svako ima svoju ulogu u efikasnom upravljanju gotovinom. Bolja vizija i razumevanje operativnog ciklusa gotovine vodi boljoj disciplini i preciznijim odlukama menadžmenta. Loše navike u upravljanju gotovinom mogu da postanu deo poslovanja, posebno u periodu rasta ili kada je lako dobiti kredite. U takvim uslovima, podizanje svesti o značaju gotovine unutar kompanije može da zahteva velike promene i kompleksne odluke.
Inostrano istraživanje je ukazalo da kompanije imaju priliku da se zaštite u uslovima slabljenja tržišta i otežanih uslova za dobijanje kredita, oslobađanjem gotovine iz sopstvenog poslovanja primenom koncepta potpunog keš menadžmenta. Ovo ne treba da bude ograničeno samo na obrtni kapital, nego treba da obuhvati i imovinu u oblicima: hartija od vrednosti, dugoročnih sredstava i u oblasti politike poreza.

Domaće istraživanje (Miletić, 2014) je sprovedeno sa ciljem da se utvrdi stanje primene u domaćoj privrednoj praksi postulata strategije „potpunog keš menadžmenta” u odnosu na kriterijum veličine preduzeća i to da li se odgovori od strane ispitanika međusobno ne razlikuju. $\mathrm{U}$ navedenom smislu postavljena je osnovna hipoteza:

$\mathrm{H}_{0}-$ ne postoje razlike među preduzećima različite veličine u Republici Srbiji u pogledu stanja prakse upravljanja tokovima gotovine.

Ukoliko se pokaže da je verovatnoća nepostojanja razlika među preduzećima različite veličine u frekvencijama odgovora manja od $\mathrm{p}=0,05$ odnosno $\mathrm{p}=0,01$ postoji osnov da se prihvati alternativna hipoteza da razlike među preduzećima različite veličine u odnosu na posmatrani aspekt primene strategije upravljanja gotovinom postoje. 


\section{METODI I MATERIJALI}

Inostrano istraživanje koje je sproveo KPMG je imalo za cilj da identifikuje: nivo važnosti gotovine u kompanijama, kako sprovode strategije upravljanja gotovinom i kako se upravljačke odluke prilagođavaju uslovima promenjenih globalnih uslova finansiranja KPMG (2008a). Treba naglasiti da je KPMG sprovela slična istraživanja i u drugim delovima sveta (KPMG, 2008b). Ukupno 152 ispitanika učestvovalo je u istraživanju u raznim zemljama Azije i Pacifika. Od tog broja 23\% ispitanika locirana su u Kini (uključujući Hong Kong), 14\% kompanija je bilo iz Japana i 35\% iz jugoistočne Azije. Većina ispitanika je iz oblasti industrije, maloprodaje, logistike, proizvodnje, hemijske i automobilske industrije. Istraživanje je pokazalo interesantnu pojavu, da mnoge kompanije koriste gotovinu iz sopstvenog tekućeg poslovanja za razvoj, bez obzira na nesigurne ekonomske uslove. Pokazalo se, takođe, da se gotovina generisana iz sopstvenog poslovanja opreznije troši.

Domaće istraživanje je sprovedeno 2011. godine putem upitnika i obuhvatio je pitanja usmerena na to da se sagleda stanje u vezi sa korišćenjem izveštaja o tokovima gotovine i upravlja obrtnim kapitalom. U tom smislu formulisana su pitanja: o značaju koji se pridaje analizi likvidnosti i solventnosti od strane menadžmenta u Republici Srbiji, glavnim teškoćama za učestalije sastavljanje izveštaja o tokovima gotovine, optimalnoj dinamici planiranja i predikcijama tokova gotovine kao i stimulisanosti menadžmenta za strukturiranje imovine i aktivnosti koje će generisati više gotovine u poslovanju. Pitanja je trebalo da pokažu u kojoj su meri postulati globalne strategije „potpunog keš menadžmenta” primenjeni u praksi upravljanja gotovinom i obrtnim kapitalom u Republici Srbiji.

U izboru ispitanika primenjen je metod slobodnog uzorka iz baze podataka Regionalne privredne komore Novi Sad. Reprezentativan uzorak je činilo 250 privrednih subjekata odabranih tako da ravnomerno budu zastupljena preduzeća u odnosu na veličinu i delatnost. Upitnik je poslat ispitanicima u elektronskoj formi.

Od ukupnog broja poslatih upitnika vraćeno je 21,60\% što predstavlja zadovoljavajući odziv. Statistička obrada podataka u domaćem istraživanju je obuhvatila frekvencionu analizu učestalosti ponuđenih odgovora u celom uzorku. Statistička značajnost razlika u učestalosti pojedinih odgovora između malih, srednjih i velikih preduzeća testirana je primenom Hi kvadrat testa. Rezultati statističke obrade prikazani su putem verovatnoće - da li se odgovori od strane preduzeća različite veličine međusobno ne razlikuju $(p)$. Za potrebe statisitičke obrade podataka korišćen je softver IBM SPSS Statistics 19.

\section{REZULTATI, DISKUSIJA I POSLEDICE}

Osnovna hipoteza iz domaćeg istraživanja je testirana putem odgovora ispitanika iz uzorka. Rezultati su iskazani u narednoj tabeli 1.

Rezultati statističke obrade prikazani putem verovatnoće (p) - su potvrdili osnovnu hipotezu da se odgovori od strane preduzeća različitih veličina međusobno ne razlikuju pa nije bilo osnova da se osnovna hipoteza odbaci.

Rezultati domaćeg i inostranog istraživanja govore: o značaju likvidnosti i solventnosti i glavnim motivima za planiranje tokova gotovine u budućnosti, glavnim razlozima netačnosti prognoza i teškoćama pri sastavljanju izveštaja o tokovima gotovine, o optimalnom periodu za pripremu i predikcije tokova gotovine, o odnosu vremenskog predviđanja i unapređenja obrtnog kapitala kao i o stimulisanosti menadžera u domenu unapređenja obrtnog kapitala i upravljanja tokovima gotovine.

Važnost upravljanja gotovinom - Međunarodno istraživanje ističe da je gotovina jedan od najosetljivijih segmenata svakog poslovanja. Poslovanje može da stvori profit, ali bez gotovine poslovanje ne može da preživi. Potencijalni benefit upravljanja gotovinom uključuje: unapređenje postojećeg poslovanja, povećanje perioda predviđanja i poverenja u tačnost informacija, unapređenje ključnih funkcija poslovanja, menjanje uobičajenih postavki i shvatanja u organizaciji i unapređenje performansi profita. Takođe, veoma je važno da se osim obrtnog kapitala posmatraju i druge oblasti, uključujući restrukturiranje bilansa stanja. Strategija „potpunog keš menadžmenta” pored toga što štiti kompanije od rizika, direktno popravlja poslovne rezultate kompanija i pomaže njihov rast. U sprovedenom međunardnom istraživanju od pristiglih odgovora, $73 \%$ ispitanika reklo je da je upravljanje gotovinom od velike važnosti ili suštinske važnosti za strategijsko upravljanje kompanijom.

Na pitanje o značaju koju analizi likvidnosti i solventnosti pridaje menadžment u Republici Srbiji odgovori isipitanika su prikazani na sledećeoj slici:



Slika 1. Značaj koji analizi likvidnosti i solventnosti pridaje menadžment u Republici Srbiji

Tabela 1. Pitanja koja su statistički obrađena a nisu iskazala statistički značajnu razliku u frekvencijama odgovora među ispitanicima $\left(\mathrm{P}^{\star}\right)$

Istraživanje: Upravljanje tokovima gotovine u odnosu na kriterijum veličine preduzeća u Republici Srbiji

$\left(P^{*}\right)$

\begin{tabular}{lc}
\hline Značaj koji analizi likvidnosti i solventnosti pridaje menadžment u Republici Srbiji & $p=0,133$ \\
\hline Glavne teškoće za učestalije sastavljanje izveštaja o tokovima gotovine & $p=0,781$ \\
\hline Otimalna dinamika planiranja budućih tokova gotovine & $p=0,881$ \\
\hline Stimulisanost menadžmenta za strukturiranje imovine i aktivnosti koje će generisati više gotovine u poslovanju & $p=0,149$
\end{tabular}

*verovatnoća da ne postoje razlike među preduzećima različitih veličina. 
Rezultati istraživanja govore da ispitanici u Republici Srbiji većinski smatraju da menadžment „nadprosečno” pridaje značaj analizi likvidnosti i solventnosti. Više od trećine ispitanika iskazuje stav o prosečnoj značajnosti a procenat ispitanika koji smatraju da menadžment malo pridaje značaj navedenim performansama je zanemarljiv. Slične zaključke su izveli: Staubus (1989), Broome, (2004), Cheng \& Hollie (2008).

Generalno možemo zaključiti da menadžment u kompanijama visokorazvijenih tržišnih ekonomija kao i u Republici Srbiji vidi i razume značaj obrtnog kapitala. Kod menadžmenta postoji svest o tome da su u vremenu krize likvidnost i solventnost performanse koje imaju prioritet kako bi se kompanije konsolidovale i stvorile pretpostavke za rast i razvoj na stabilnim osnovama. Značajan instrument adekvatne analize likvidnosti i solventnosti je izveštaj o tokovima gotovine.

Veza sa profitabilnošću - Međunarodno istraživanje ističe da je upravljanje gotovinom više nego postizanje većeg profita. Istraživanje pokazuje da ostvarivanje profita nije $\mathrm{u}$ direktoj vezi sa sastavljanjem tokova gotovine budućeg perioda. Samo $47 \%$ ispitanika vidi porast profita kao osnovni razlog za predviđanje tokova gotovine, dok primarni razlozi uključuju potrebu uvođenja kontrole gotovine u odnosu na njeno raspoloživo stanje i moguće nedostatke, izbegavanje lošeg upravljanja gotovinom i definisanje odgovornosti za upravljanje gotovinom. Napred navedeno iskazuje sledeći grafikon:

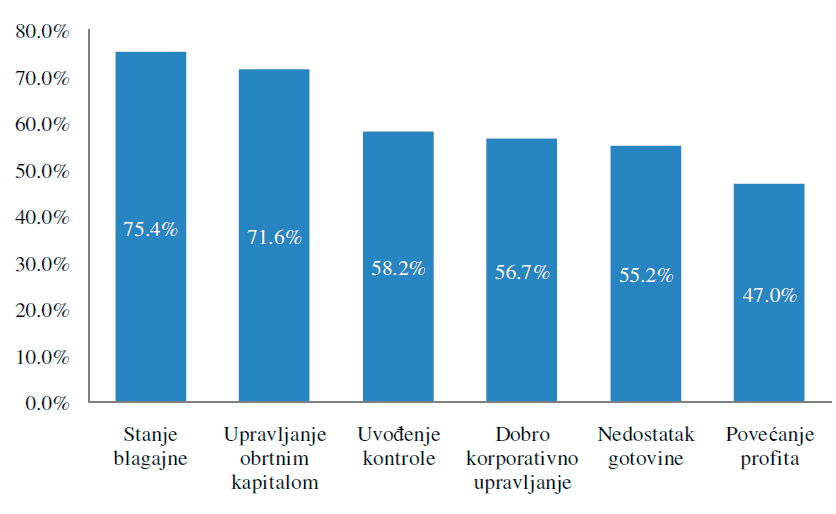

Slika 2. Glavni razlozi za pripremanje tokova gotovine $\mathrm{u}$ budućem vremenu

Između ispitanika, oni sa preciznijim predviđanjima tokova gotovine su ostvarili, u proseku, povećanje profita za $10,1 \%$. Oni koji su imali manje precizna predviđanja imali su povećanje profita za samo $2,6 \%$.

Razlozi netačnosti prognoza - Precizno predviđanje cash flow-a, uz upravljanje naplatom od kupaca i plaćanja obaveza, omogućuje efikasnije upravljanje gotovinom u željeno vreme, uočavanje sezonskih trendova i rizika i pomaže vlasnicima da koriguju svoja očekivanja. Predviđanje je kritičan korak u keš menadžmentu u cilju povećavanja profitabilnosti. Kao najčešći uzrok netačnosti u predviđanju, ispitanici iz međunarodnog istraživanja kao najbitnije navode po redosledu važnosti: nepredviđene spoljne faktore, zatim vremenski raspon i kao treći faktor po značaju ističu da su pretpostavke u predviđanju bile pogrešne. Uočava se da je procenat nepredviđenih spoljnih faktora najveći što govori o kompleksnosti ovakvih prognoza. Preporuka bazirana na „potpunim keš strategijama” je da se kvalitet obrtnog kapitala procenjuje minimum dva puta godišnje da bi se otkrili problemi u sistemu.

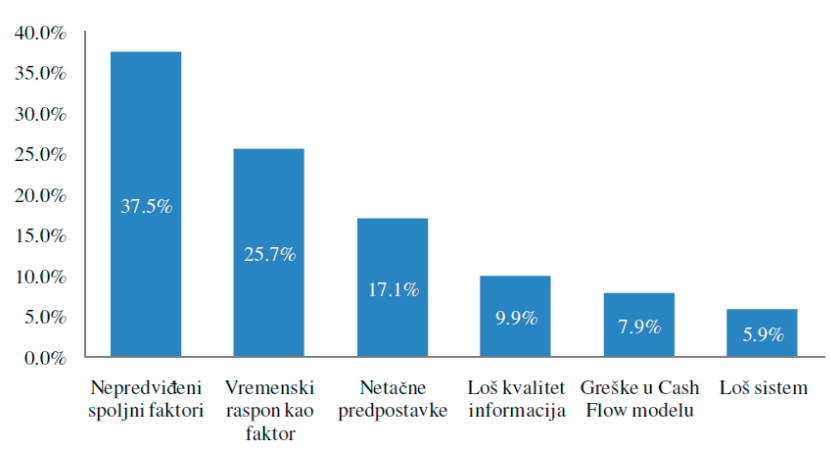

Slika 3. Razlozi netačnosti prognoza

U domaćem istraživanju formulisano je pitanje o Glavnim teškoćama za učestalije sastavljanje izveštaja o tokovima gotovine, koje je trebalo da istakne najveća ograničenja u vezi sa učestalijim satavljanjem izveštaja o tokovima gotovine u finansijskom upravljanju o čemu govori naredna slika:

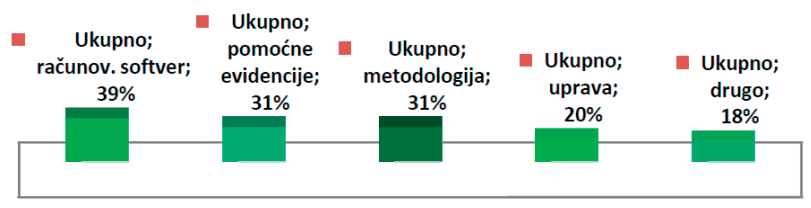

Slika 4. Glavne teškoće za učestalije sastavljanje izveštaja o tokovima gotovine

Analiza dobijenih rezultata upućuje na nedovoljno usavršen računovodstveni softver kao glavnu teškoću za učestalije sastavljanje izveštaja o tokovima gotovine. Na drugom mestu, ravnopravno se nalaze nedovoljno razrađene pomoćne evidencije i nedovoljno poznavanje metodologije sastavljanja izveštaja o tokovima gotovine, ređe se kao teškoća prepoznaje praksa da uprava ne traži češće sastavljanje izveštaja o tokovima gotovine.

Zaključci koji su iskazani u vezi sa istraživanjem domaće prakse imaju sličnosti za rezultatima koji su dobijeni u međunarodnom istraživanju. Oba istraživanja upućuju na preporuku za organizovanjem sistema upravljanja i kontrole tokova gotovine i upotrebe obrtnog kapitala. Takav sistem podrazumeva organizaciju kompanije sa stanovišta obuke odgovornih lica, tehničke pretpostavke i čvrstu opredeljenost menadžmenta da ovakav sistem unapređuje.

Vremenski period u predviđanju - Rezultati međunarodnog istraživanja govore da za mnoge kompanije, period predviđanja kraći od mesec dana neće dati nikakve vredne rezultate. Unapređenje obrtnog kapitala od $10 \%$ su imale kompanije čiji je vremenski period predviđanja preko 3 do 6 meseci. Domaće istraživanje govori o preferencijama u planiranju tokova gotovine od strane menadžera domaćih preduzeća po kriterijumu veličine pravnog lica. Dajemo uporedni prikaz rezultata oba istraživanja: 

Ukupno u uzorku;
dnevno;
$9,26 \%$
- Ukupno u uzorku; nedeljno;

$14,81 \%$
Ukupno u uzorku; mesečno;

$27,78 \%$
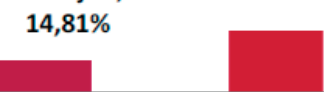
Ukupno u uzorku;
tromesečno;

$14,81 \%$
- Ukupno u uzorku; polugodišnje;

$11,11 \%$
Ukupno u uzorku; drugo; $9,26 \%$

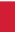

Slika 5. Otimalna dinamika planiranja budućih tokova gotovine domaće istraživanje kriterijum veličine preduzeća

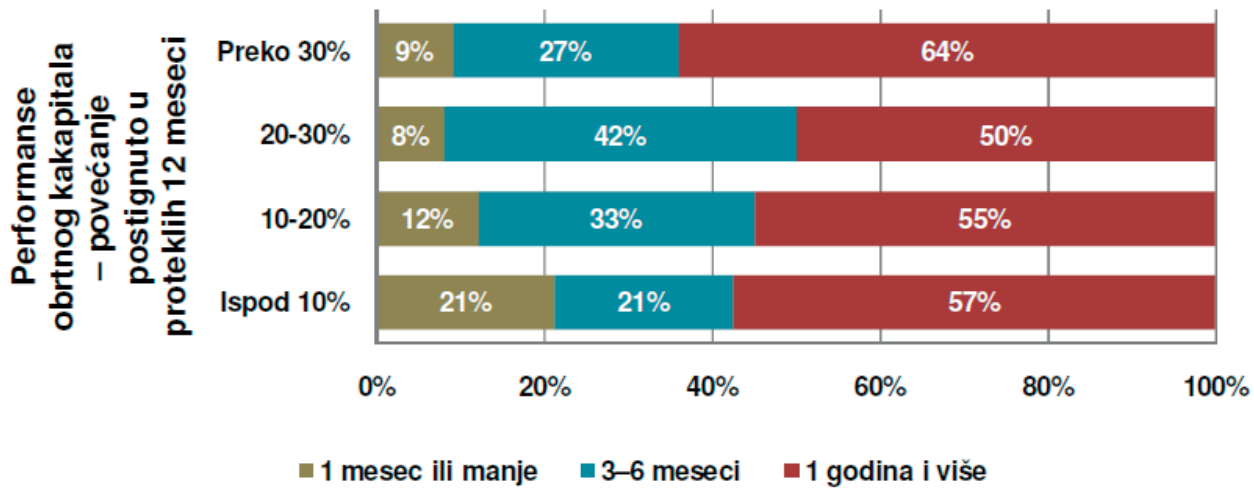

Slika 6. Odnos vremenskog perioda predviđanja i unapređenja obrtnog kapitala inostrano istraživanje

Rezultati domaćeg istraživanja govore da je preovlađujući optimalni period planiranja na mesečnom nivou. Preferencije ispitanika po pitanju tromesečnog, polugodišnjeg i godišnjeg planiranja su približno iste i zbirno čine približno trećinu ispitanika.

Generalno se može zaključiti da domaća preduzeća u cilju povećanja profitabilnosti i racionalnijeg korišćenja obrtnog kapitala treba da praktikuju duži vremenski horizont u planiranju tokova gotovine od tri meseca do godinu dana i duže, u cilju unapređenja upravljanja tokovima gotovine i obrtnog kapitala.

Stimulacija menadžmenta za unapređenje upravljanja obrtnog kapitala - Međunarodno istraživanje ukazuje da je sagledavanje ključnih faktora performansi - KPI (Key Performance Indicators - ili tabela sa upravljačkim rezultatima) suština preciznosti predviđanja. Praksa inostanih kompanija je korišćenje KPI koje se koriste u merenju rezultata zaposlenih i donosilaca odluka. Na osnovu objektivno izmerenih parametara moguće je povezati rezultate u upravljanju obrtnim kapitalom i plate menadžera kao stimulativni faktor strategije „potpunog keš menadžmenta”. Ispitanici u Australiji i Maleziji su najčešće koristili pristup ključnih faktora u primeni koncepta potpunog keš menadžmenta.

U domaćem istraživanju ispitanicima je postavljeno pitanje o stimulisanosti menadžmenta kao faktoru unapređenja efikasnosti imovine u generisanju gotovine. Rezultati su prikazani u narednoj tabeli:

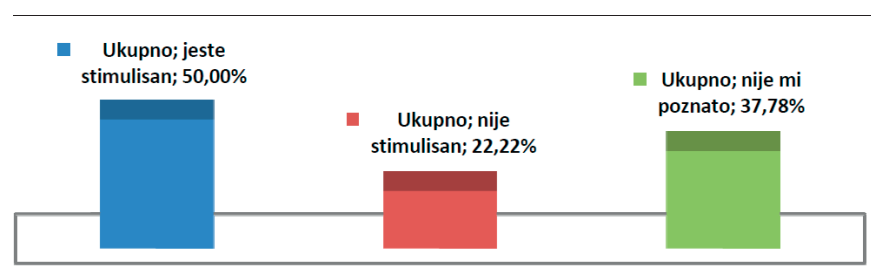

Slika 7. Stimulisanost menadžmenta za strukturiranje imovine i aktivnosti koje će generisati više gotovine u poslovanju
Dobijeni rezultati u domaćem istraživanju govore da polovina ispitanika u uzorku smatra da praksa stimulacije menadžmenta postoji dok polovina ispitanika smatra da menadžeri nisu stimulisani ili da im to nije poznato. Ovo govori o tome da praksa podsticanja menadžmenta putem novčanih bonusa ka ostvarenju ciljeva unapređenja obrtnog kapitala još nije dominantno zaživela u našoj privrednoj praksi i da ovu praksu treba unaprediti u skladu sa dobrom praksom strategija upravljanja tokovima gotovine u razvijenim tržišnim privredama.

\section{ZAKLJUČAK}

Primena strategije „potpunog keš menadžmenta” ne podrazumeva samo upravljanje obrtnim kapitalom, to je upravljanje koje ulazi i u druge oblasti poslovanja i podrazumeva upravljanje bilansom stanja i bilansom uspeha iz aspekta upravljanja tokovima gotovine, sa ciljem da je ovakvo upravljanje gotovinom deo strategijskog upravljanja poslovnim procesima. Ovo podrazumeva: razumevanje tokova gotovine u celokupnom poslovanju, predviđanje potreba za gotovinom, povećanje transparentnosti tokova gotovine, povećanje kontrole gotovine, definisanje odgovornosti zaposlenih za korišćenje gotovine, uvođenje mogućnosti „generisanja gotovine iz obrtnog kapitala i ostalih delova bilansa stanja", čuvanje gotovine u periodu kada je to najneophodnije i uvođenje postojanog i sistematskog unapređenja kulture korišćenja gotovine.

U skladu sa ciljem rada prikazali smo uporedo rezultate međunarodnog i domaćeg istraživanja u vezi sa primenom postulata strategije „potpunog keš menadžmenta”.

Može se zaključiti da u pogledu značaja koji domaći menadžmet pridaje obrtnom kapitalu i tokovima gotovine postoji znatno slaganje sa rezultatima međunarodnih istraživanja koja govore da su ova pitanja u vrhu korporativnih 
prioriteta i nadprosečno su značajna za inostrani i domaći menadžment.

Po pitanju glavnih teškoća u unapređenju prakse upravljanja tokovima gotovine postoji slaganje inostranog i domaćeg istraživanja pre svega u pretpostavkama koje treba uvesti da bi došlo do unapređenja navedene prakse. Reč je o organizacionim aspektima: kontroli i definisanju odgovornosti u upravljanju tokovima gotovine koje ispitanici ističu. Ispitanici smatraju bi se navedene mere pre svega odrazile na efikasnost upravljanja obrtnim kapitalom, a sekundarno bi imale uticaj na povećanje profitabilnosti.

Ako je reč o dominantnom stavu o optimalnom periodu predikcije tokova gotovine sa efektima na profitabilnost, inostrana praksa zastupa stav da je optimalni period predviđanja duži od tri meseca, a preporučuju se i dugoročnije predikcije tokova gotovine. Istraživanje domaće prakse je potvrdilo da dominira planiranje tokova gotovine na mesečnom nivou ali da trećina ispitanika smatra optimalnu praksu planiranja od tri meseca i duže.

Razvijena praksa uvođenja sistema bonusa za menadžment kao stimulacija za dobre rezultate u unapređenju obrtnog kapitala u inostranoj praksi je prisutna i u domaćoj praksi ali još nije dominantna. Rezultati istraživanja ukazuju da je potrebno unaprediti podsticanje menadžera u domaćoj privrednoj praksi u skladu sa preporukama strategije „potpunog keš manadžmenta”.

\section{LITERATURA}

Broome, O.W. (2004). Statement of Cash Flows: Time for Change! Financial Analysts Journal of CFA Institute, 60(2), 16-22.

Cheng, C.S.A., \& Hollie, D. (2008). Do core and non-core cash flows from operations persist differentially in predicting future cash flows? Review of Quantitative Finance and Accounting 31(1), 29-53.

KPMG Canada. (2008a). Clawing Back Cash: Developing a Total Cash Management Strategy. KPMG's Restructuring Services group commissioned mergermarket to survey executives at mid-sized organisations around Asia Pacific. Retrieved from https://www.kpmg.com/AU/en/IssuesAndInsights/ArticlesPublications/Documents/Clawing-back-cash-Developing-a-total-cash-management-strategy.pdf

KPMG Canada. (2008b). The importance of preserving cash in a downturn: a report prepared by CFO Europe Research in colaboration with KPMG. Retrieved from https://www. kpmg.com/LU/en/IssuesAndInsights/Articlespublications/ Documents/Preserving-cash-in-downturn-kpmg.pdf

Miletić, D. (2014). Cash flow statement: Assessment of situation and application problems in Serbia. Industrija, 42(4), 99114. doi: 105937/industrija42-6955

Staubus, J.G. (1989). Cash Flow Accounting and Liquidity: Cash Flow Potential and Wealth. Accounting and Business Research, 19(74), 161-169.

\section{CASH MANAGEMENT STRATEGIES AS A GOOD GLOBAL BUSINESS PRACTICE}

\begin{abstract}
:
Cash and working capital are the main corporate priorities. Some of the well-known auditing companies have defined the business strategy of 'complete cash management' in order to specify criteria and measurements for more efficient cash management in a highly competitive business environment. It is a business strategy of cash management that aims to create value for the owners and strengthen profit margins. In order to compare the use of the given cash management strategy and working capital in the Republic of Serbia with its use in the foreign companies, research was conducted to determine the current situation concerning the relevant elements of the 'complete cash management strategy'. Based on the responses obtained, certain similarities were observed, which are primarily related to the importance assigned to cash flow management, liquidity and solvency by managers in foreign and local companies. The research also revealed similarities between practices in terms of defining the issue of working capital improvement and the ways of achieving the desired goals.

A comparative analysis indicates certain differences between the foreign and local companies in terms of optimum period for cash flow predictions and practice of encouraging managers to improve cash management through bonuses. The situation observed requires more active implementation of 'complete cash management strategy' in companies in the Republic of Serbia.
\end{abstract}

\section{Key words:}

working capital, cash flows,

business strategy, predictions, measurements. 